\title{
Depression, alcohol abuse, and disclosure of HIV serostatus among rural HIV-positive individuals in western Uganda
}

This article was published in the following Dove Press journal:

Neurobehavioral HIV Medicine

13 April 201 |

Number of times this article has been viewed

\section{E Nakimuli-Mpungu' ${ }^{1,2}$ \\ G Munyaneza ${ }^{3,4}$}

'Mental Health Department, Johns Hopkins Bloomberg School of Public Health, Baltimore, MD, USA; ${ }^{2}$ Department of Psychiatry, Makerere College of Health Sciences, School of Medicine, Kampala, Uganda; ${ }^{3}$ Butabika School of Psychiatric Clinical Officers, Ministry of Education, Kampala, Uganda; ${ }^{4}$ Rushere Community Hospital, Rushere, Uganda
Correspondence: Etheldreda NakimuliMpungu

Johns Hopkins Bloomberg School of Public Health, Mental Health Department, 624 N Broadway, Hampton House, Rm 784, Baltimore, MD 21205, USA

Tel +l 4438394012

Email enakimul@jhsph.edu
Introduction: Research into psychological factors associated with disclosure of human immunodeficiency virus (HIV) serostatus in low resource settings is limited. The primary aim of this study was to determine the relationship between depression, alcohol abuse, and disclosure of HIV serostatus to social networks.

Methods: We performed a cross-sectional study in which 244 HIV-positive individuals were examined for disclosure of HIV-positive serostatus and assessed for DSM-IV (Diagnostic Statistical Manual, fourth edition)-defined major depression and alcohol abuse disorder. Multiple regression models were used to determine factors independently associated with major depression, alcohol abuse, and disclosure of HIV serostatus.

Results: Of the 244 study participants, the majority $210(86 \%)$ had disclosed their HIV serostatus. Among those who disclosed their HIV serostatus, 48 (23\%) regretted this disclosure. The majority (40\%) met DSM-IV criteria for depression, while (7.8\%) met DSM-IV criteria for alcohol abuse. Disclosure was protective against alcohol abuse (odds ratio $[\mathrm{OR}]=0.21$; $P=0.016)$ but not depression $(\mathrm{OR}=0.68 ; P=0.38)$; and was associated with time since HIV diagnosis $(\mathrm{OR}=1.39 ; P=0.007)$ and HIV pretest counseling $(\mathrm{OR}=3.9 ; P=0.045)$.

Conclusion: Disclosure of HIV serostatus was protective against alcohol abuse but not depression, while regret of disclosure was significantly associated with depression.

Keywords: alcohol abuse, HIVstatus, depression, disclosure

\section{Introduction}

One of the challenges faced by PLWHAs (persons living with human immunodeficiency virus [HIV] or acquired immune deficiency syndrome [AIDS]) is the decision about whether or not to disclose their HIV serostatus to their social networks. HIV disclosure is a sensitive issue, often causing psychological distress due to the uncertainty of how people will react. ${ }^{1-3}$ Although partners, family members, and friends may provide security and serve as sources of emotional support, the prejudice and discrimination directed towards PLWHAs may significantly impact this network of significant relationships. ${ }^{4,5}$

Lack of disclosure of HIV status has been associated with personal distress and loneliness. ${ }^{6}$ Indeed, expecting rejection due to stigma is associated with denial, deception, and social withdrawal, which leads to more constricted social networks and low self-esteem. ${ }^{7}$ The fear of being found out by the community, of disgracing one's self and family, and of mistreatment by health care workers are related indirectly to health seeking intentions and behaviors. ${ }^{8}$ Furthermore, social avoidance or rejection can then, of course, hinder peoples' psychological and physical wellbeing. 
Existing research regarding HIV disclosure has primarily focused on documenting rates of disclosure, ${ }^{9}$ predictors of disclosure, ${ }^{10}$ issues regarding disclosure to children, ${ }^{11-13}$ and individuals to whom PLWHA disclose their serostatus. ${ }^{14-16}$ Research on the relationship between disclosure and mental health problems (in particular, depression and alcohol abuse) has produced mixed findings and has been conducted largely in HIV-positive populations from developed countries. Some studies have found an association between disclosure and lower levels of depression, ${ }^{10,17,18}$ while other studies have reported higher levels of depression being associated with disclosure of HIV serostatus, ${ }^{19}$ and others have reported no association between depression and disclosure. ${ }^{14,20}$

This pilot study was designed to explore the prevalence of depression and alcohol abuse among HIV-positive individuals attending a rural HIV clinic in western Uganda. We hypothesized that there would be high rates of depression and low rates of alcohol abuse in this study population. We also aimed to determine the relationship between these mental health problems and disclosure of HIV status to family and friends. We hypothesized that disclosure of HIV status to either family or friends would be protective against depression symptoms and alcohol abuse. However, those who regretted disclosing their HIV status would have more prevalence rates of depression and alcohol abuse than those who did not regret their disclosure.

\section{Methods}

\section{Participants}

A total of 244 HIV-positive individuals participated in the study; $64 \%$ were female, $53 \%$ had primary level education, and $58 \%$ were unemployed. The participant age range was $18-60$ years $($ mean $=36.2$, standard deviation $[\mathrm{SD}]=8.9)$; $52 \%$ were married or cohabiting, $6.6 \%$ were single, $15 \%$ were divorced/separated, and $26 \%$ were widowed. The majority $(60 \%)$ had four or more children. Details of the demographic characteristics are shown in Table 1.

\section{Recruitment}

Over a 3-month period (October 2004-March 2005), we performed a cross-sectional study of adult HIV-positive individuals who were recruited through an outpatient HIV clinic in Rushere Community Hospital, situated in the Kiruhura district in western Uganda, about 20 miles south of the equator. The hospital was opened in 1992 as a nongovernmental hospital, owned by the community and also as a health subdistrict headquarters after a memorandum of
Table I Demographic characteristics of HIV positive individuals in Rushere hospital in western Uganda

\begin{tabular}{|c|c|c|}
\hline Variables & Frequency $(N=244)$ & Percentage \\
\hline \multicolumn{3}{|l|}{ District of origin } \\
\hline Kiruhura & 225 & 92.2 \\
\hline Kyenjojo & 10 & 4.1 \\
\hline Kamwenge & 5 & 2.1 \\
\hline Ibanda & 2 & 0.8 \\
\hline Others & 2 & 0.8 \\
\hline \multicolumn{3}{|l|}{ Gender } \\
\hline Males & 88 & 36.1 \\
\hline Females & 156 & 63.9 \\
\hline \multicolumn{3}{|l|}{ Age category } \\
\hline $18-30$ & 76 & 31.15 \\
\hline $31-50$ & 154 & 63.11 \\
\hline$>50$ & 14 & 5.74 \\
\hline \multicolumn{3}{|l|}{ Religion } \\
\hline Catholics & 47 & 19.3 \\
\hline Protestants & 157 & 64.3 \\
\hline Moslems & 5 & 2.1 \\
\hline Others & 35 & 14.3 \\
\hline \multicolumn{3}{|l|}{ Level of education } \\
\hline $\begin{array}{l}\text { No formal education to } \\
\text { primary level }\end{array}$ & 213 & 87.3 \\
\hline $\begin{array}{l}\text { Secondary education } \\
\text { and above }\end{array}$ & 13 & 12.7 \\
\hline \multicolumn{3}{|l|}{ Employment status } \\
\hline Employed & 8 & 3.3 \\
\hline Self employed & 81 & 33.2 \\
\hline Unemployed & 91 & 37.3 \\
\hline Retired & 13 & 5.3 \\
\hline Housewife & 51 & 20.9 \\
\hline \multicolumn{3}{|l|}{ Number of children } \\
\hline $1-4$ & 97 & 39.7 \\
\hline$>4$ & 147 & 60.2 \\
\hline \multicolumn{3}{|l|}{ Marital status } \\
\hline Single & 16 & 6.56 \\
\hline Married/cohabiting & 127 & 52.05 \\
\hline Divorced/separated & 37 & 15.16 \\
\hline Widowed & 64 & 26.23 \\
\hline
\end{tabular}

understanding with the government. It oversees 12 government health units in the area within a radius of 70 miles. Following an extensive building program, it has grown to nearly 100 beds. The HIV clinic was opened in 2005 and offers HIV counseling and testing services, treatment of opportunistic infections, and provision of antiretroviral drugs. The clinic is supported by the Ministry of Health and other nongovernmental organizations.

Patients were eligible for this study if they: 1) were receiving outpatient care at the clinic, 2) were 18 years or older, 3) did not have any debilitating illness or impaired consciousness, and 4) were able to provide written informed consent prior to participation. Study procedures were 
approved by the Butabika National Referral Psychiatric Hospital ethics review committee. All individuals requested to participate in the study, consented to do so.

\section{Measures}

\section{Demographics}

Descriptive information, including age, gender, marital, educational, and employment status, and number of children were assessed using a standardized demographic questionnaire.

\section{Disclosure of HIV status}

Disclosure of HIV status was assessed by directly questioning the study participants whether they had disclosed their HIV status to relatives or friends.

\section{Depression and alcohol abuse disorder}

The Diagnostic Statistical Manual fourth edition (DSM-IV) ${ }^{21}$ symptom criteria for depression and alcohol abuse disorder (see Appendix 1) was used to diagnose depression and alcohol abuse disorders. This instrument was translated to Lunyankole (the local language of the study participants) and back-translated into English by expert and ordinary individuals such as nurses and volunteer health workers who speak both English and Lunyankole. The translated, Lunyakole version of the DSM-IV symptom criteria for depression was adapted to include the local expressions of depression and locally observed consequences of excessive alcohol consumption. This exercise ensured that wording and question construction were comprehensible to the target population.

Individuals who endorsed five or more symptoms of depression and indicated that these symptoms had caused significant problems at home, at work, socially, or at school or in some other important way were diagnosed as having depression. Individuals who reported a maladaptive pattern of alcohol use in the previous 12 months characterized by intoxication more than once which interfered with their ability to fulfill responsibilities at home, at work, or at school were diagnosed with alcohol abuse disorder.

\section{Statistical analysis}

Statistical analysis was carried out with STATA statistical software (v 10; Stata Corp, College Station, TX). Frequencies of clinical and demographic variables were computed, and bivariate analyses were conducted to identify demographic and clinical variables that were significantly correlated with disclosure of HIV status. For the bivariate analyses, we used chi-square tests or Fisher's exact test for categorical variables and independent-sample $t$-tests for continuous variables. Factors independently associated with depression, alcohol abuse, and disclosure of HIV status were assessed using multiple regression models.

\section{Results}

Of the 244 study participants, the majority $210(86 \%)$ had disclosed their HIV status. Table 2 shows the comparison of those who disclosed and those who did not disclose their HIV status. Among those who disclosed their HIV serostatus, $48(23 \%)$ regretted the disclosure. Table 3 shows the factors independently associated with disclosure of HIV status. The majority (40\%) met DSM-IV criteria for depression, while (7.8\%) met DSM-IV criteria for alcohol abuse.

\section{Characteristics of study participants with depression}

Compared with nondepressed HIV-positive individuals, depressed individuals were more likely to be female (odds ratio $[\mathrm{OR}]=2.55, P=0.001$ ), less likely to be married ( $\mathrm{OR}=0.52, P=0.013$ ), and more likely to be widowed $(\mathrm{OR}=1.75, P=0.05)$. Depressed individuals had known their HIV status for longer periods compared with nondepressed individuals [mean $(\mathrm{SD})=3.93$ (4.4) versus 2.45 (2.1); $P=0.000]$. Further, depressed individuals were more likely to have expressed regret about disclosing their HIV status compared with nondepressed individuals. Table 4 shows the factors independently associated with depression.

\section{Characteristics of study participants with alcohol abuse}

HIV-positive individuals diagnosed with alcohol abuse were more likely to be single $(\mathrm{OR}=5.03, P=0.024)$, less likely to be married (OR $=0.19, P=0.012)$, and less likely to have received HIV pre-test counseling $(\mathrm{OR}=0.2$, $P=0.006)$ and post-test counseling $(\mathrm{OR}=0.13, P=0.008)$, compared with HIV positive individuals without alcohol abuse. Further, alcohol abuse was significantly more prevalent in those HIV-positive individuals who had not disclosed their HIV status (OR $=5.5, P=0.001)$ as well as those who expressed regret after disclosing their HIV status (OR $=2.87, P=0.12$ ), compared with those who had disclosed their status and those who did not regret disclosure respectively. 
Table 2 Simple logistic regression model: factors associated with disclosure of HIV status among HIV positive individuals

\begin{tabular}{|c|c|c|c|c|}
\hline Variables & $\begin{array}{l}\text { Disclosed HIV status } \\
\mathbf{N}=210 \\
\mathrm{n}(\%)\end{array}$ & $\begin{array}{l}\text { Did not disclose HIV status } \\
\mathbf{N}=\mathbf{3 4} \\
\mathrm{n}(\%)\end{array}$ & Odds ratio & $P$-value \\
\hline Age mean (SD) & $36.5(9.3)$ & $33.5(7.7)$ & $-1.76 *$ & 0.039 \\
\hline \multicolumn{5}{|l|}{ Gender } \\
\hline Male & $73(34.76)$ & $15(44.12)$ & I & \\
\hline Female & $137(65.24)$ & $19(55.88)$ & $\mathrm{I} .48$ & 0.29 \\
\hline \multicolumn{5}{|l|}{ Marital status } \\
\hline Never married & $13(6.19)$ & $3(8.82)$ & I & \\
\hline Married & $106(50.48)$ & $21(61.76)$ & 0.61 & 0.36 \\
\hline Previously married & 91 (43.33) & $10(29.4 I)$ & 1.21 & 0.72 \\
\hline \multicolumn{5}{|l|}{ Education status } \\
\hline Primary level or less & $24(11.43)$ & 7 (20.59) & 1 & \\
\hline Secondary level or more & $186(88.57)$ & $27(79.41)$ & 2.0 & 0.14 \\
\hline Years since HIV diagnosis (mean, SD) & $3.24(3.45)$ & $1.76(1.69)$ & $-2.47^{*}$ & 0.007 \\
\hline \multicolumn{5}{|l|}{ Depression } \\
\hline No & $128(60)$ & $19(55.88)$ & I & \\
\hline Yes & $82(40)$ & $15(44.12)$ & 0.81 & 0.58 \\
\hline \multicolumn{5}{|l|}{ Alcohol abuse } \\
\hline No & $198(94.29)$ & $27(79.41 \%)$ & & \\
\hline Yes & $12(5.7 I)$ & $7(20.39 \%)$ & 0.23 & 0.005 \\
\hline \multicolumn{5}{|l|}{ Received HIV pre-test counseling } \\
\hline No & $15(7.14)$ & $9(26.47)$ & & \\
\hline Yes & $195(92.86)$ & $25(73.53)$ & 4.68 & 0.001 \\
\hline \multicolumn{5}{|l|}{ Received HIV post-test counseling } \\
\hline No & $6(2.86)$ & $4(I I .76)$ & I & \\
\hline Yes & $204(97.14)$ & $30(88.24)$ & 4.53 & 0.001 \\
\hline
\end{tabular}

Note: $*_{\text {t-test. }}$

\section{Discussion}

In keeping with our hypothesis, high rates of depression and low rates of alcohol abuse were found in this study population in western Uganda. This finding is comparable with what previous studies conducted in Uganda have found. A study in eastern Uganda found that $47 \%$ of HIV-positive individuals had significant depression symptoms. ${ }^{22}$ Other studies have reported estimates of depression symptoms ranging from $30 \%-54 \%{ }^{23,24}$ Prevalence rates of alcohol also fall within the range that has been described in HIV-positive populations in developed and developing countries. In North

Table 3 Multivariate logistic model: factors independently associated with disclosure of HIV status

\begin{tabular}{llll}
\hline Variable & $\begin{array}{l}\text { Adjusted } \\
\text { odds ratio }\end{array}$ & $\mathbf{9 5 \% ~ C l ~}$ & P-value \\
\hline Alcohol abuse & 0.21 & $0.06-0.75$ & 0.016 \\
$\begin{array}{l}\text { Having secondary education } \\
\text { or more }\end{array}$ & 1.98 & $0.69-5.67$ & 0.19 \\
$\begin{array}{l}\text { Depression } \\
\text { Years since HIV diagnosis }\end{array}$ & 0.68 & $0.28-1.61$ & 0.38 \\
$\begin{array}{l}\text { Received HIV pre-test } \\
\text { counseling }\end{array}$ & 1.39 & $1.09-1.77$ & 0.007 \\
\hline
\end{tabular}

America, a systematic review by Hendershot et $\mathrm{al}^{25}$ found prevalence rates of alcohol use disorders to range from $9 \%-15 \%$. Studies from South Africa ${ }^{26,27}$ report on estimates ranging from $2.5 \%-10 \%$.

Consistent with previous studies, ${ }^{28,29}$ there were high rates of disclosure of HIV status in this study population. Previous studies have confirmed that when people living with HIV disclosed their status to more people, they reported more social support. ${ }^{30}$

Disclosure of HIV serostatus was significantly more likely to occur in those that had known their HIV status for longer periods and those who had received HIV pre-test counseling. These findings are consistent with what has been reported in

Table 4 Multivariate logistic model: factors independently associated with depression among HIV positive individuals

\begin{tabular}{llll}
\hline Variable & $\begin{array}{l}\text { Adjusted } \\
\text { odds ratio }\end{array}$ & 95\% Cl & P-value \\
\hline Years since HIV diagnosis & 1.20 & $1.05-1.33$ & 0.004 \\
Having 4 or more children & 0.46 & $0.23-0.94$ & 0.034 \\
Age & 1.04 & $0.99-6.45$ & 0.07 \\
Gender & 2.97 & $1.37-1.77$ & 0.006 \\
Regret of disclosure of HIV status & 3.6 & $1.73-7.49$ & 0.045 \\
\hline
\end{tabular}


the literature. Serovich et $\mathrm{al}^{31}$ investigated time to disclosure of HIV status and found that more disclosure occurred as the number of years since HIV diagnosis increased, with the majority of patients revealing their status within the first 7 years of diagnosis. Interventions such as HIV pre-test and post-test counseling have been previously found to significantly correlate with disclosure of HIV status. ${ }^{32}$

In keeping with our hypothesis, depression and alcohol abuse were less prevalent among those who had disclosed their HIV status compared with those who had not disclosed, although the association was only significant for alcohol abuse. The significant negative association between alcohol abuse and disclosure of HIV status is unique to this study. Previous studies in which substance use has been assessed have not found any correlation between alcohol abuse and disclosure of HIV status. ${ }^{33,34}$

Although, there were few individuals who regretted their decision to disclose their HIV status, those who did had more rates of depression and alcohol abuse than those who did not disclose their HIV status. These findings affirm that disclosure is a complex process with widely varying consequences. Although it may result in greater social support, negative consequences such as feelings of regret and undermining reactions from close friends, intimate partners, and parents have been associated with depression and anxiety. ${ }^{10,35-37}$

Interestingly, individuals with alcohol abuse were significantly less likely to have received HIV pre-test and post-test counseling, suggesting that these pre-notification measures may be protective against maladaptive behaviors in the face of an HIV diagnosis. Indeed, previous studies have found a decrease in sexual risk behaviors following HIV counseling and testing among HIV-positive individuals.

However, results from this research must be viewed within the context of the following limitations. Firstly, the crosssectional nature of this study limits our ability to interpret causal direction in the findings. Secondly, we did not ask when disclosure occurred with each of these participants, and the different targets of exposure were not investigated. Research has shown that there may be a different impact of disclosure depending on the targets of disclosure. ${ }^{38}$ Further, the impact of disclosure may be different in the period immediately following the disclosure than that occurring later. It is possible that the positive effects of disclosure may diminish over time and other factors such as stressful life events, medication adverse effects, and symptomatic disease may override the initial effect of disclosure. These factors are potential confounders that were not controlled for in this study.

\section{Conclusion}

Disclosure of HIV status was independently associated with longer periods since HIV diagnosis and HIV pre-test counseling in this study population. Disclosure of HIV status was protective against alcohol abuse but not depression. Regret of disclosure was significantly associated with depression.

There is a need for continued research with African HIV-positive populations to identify background and contextual variables that may uniquely influence disclosure of HIV status so that evidence-based strategies that address stressors related to disclosure can be implemented.

\section{Disclosure}

The authors report no conflicts of interest in this work.

\section{References}

1. Lee MB, Rotheram-Borus MJ. Parents'disclosure of HIV to their children. AIDS. 2002;16:2201-2207.

2. Clark HJ, Lindner G, Armistead L, Austin B-J. Stigma, disclosure and psychological functioning amount HIV-infected and non-infected African-American women. Women Health. 2003;38:57-71.

3. Landau G, York A. Keeping and disclosing a secret among people with HIV in Israel. Health Soc Work. 2004;29:116-126.

4. Derlega VJ, Winstead BA, Folk-Barron L. Reasons for and against disclosing HIV-seropositive test results to an intimate partner: a functional perspective. In: Petronio S, editor. Balancing the Secrets of Private Disclosures. Mahwah, NJ: Lawrence Erlbaum; 2000: 53-69.

5. Wiener LS, Battles HB, Heilman N. Public disclosure of child's HIV infection: impact on children and families. AIDS Patient Care STDS. 2000;12:485-497.

6. Wiener LS, Battles HB, Heilman N. Public disclosure of child's HIV infection: impact on children and families. AIDS Patient Care STDS 2000; $12: 485-497$.

7. Markowitz FE. The effects of stigma on the psychological well-being and life satisfaction of persons with mental illness. J Health Soc Behav. 1998;39:335-348.

8. Smith RA, Morrison D. The impact of stigma, experience and group referent on HIV risk assessments and HIV testing intentions in Namibia. Soc Sci Med. 2006;63:2649-2660.

9. Kalichman SC, Nachimson D. Self-efficacy and disclosure of HIVpositive serostatus to sex partners. Health Psychol. 1999;18:281-287.

10. Hays RB, McKusick L, Pollack L, Hilliard R, Hoff C, Coates TJ Disclosing HIV seropositivity to significant others. AIDS. 1993;7: 425-431.

11. Kirshenbaum SB, Nevid JS. The specificity of maternal disclosure of HIV/AIDS in relations to children's adjustment. AIDS Educ Prev. 2002;14:1-16.

12. Letteney S, LaPorte HH. Deconstructing stigma: perceptions of HIVseropositive mothers and their disclosure to children. Soc Work Health Care. 2004;38:105-123.

13. Mellins CA, Kang E, Leu C, Havens JF, Chesney MA. Longitudinal study of mental health and psychosocial predictors of medical treatment adherence in mothers living with HIV disease. AIDS Patient Care STDS. 2003;17:407-416.

14. Simoni JM, Davis ML, Drossman JA, Weinberg BA. Mothers with HIV/ AIDS and their children: disclosure and guardianship issues. Women Health. 2000;31:39-54. 
15. Kirshenbaum SB, Nevid JS. The specificity of maternal disclosure of HIV/AIDS in relations to children's adjustment. AIDS Educ Prev. 2002; $14: 1-16$.

16. Letteney S, LaPorte HH. Deconstructing stigma: perceptions of HIVseropositive mothers and their disclosure to children. Soc Work Health Care. 2004;38:105-123.

17. Armistead L, Morse E, Forehand R, Morse P, Clark L. African-American women and self-disclosure of HIV infection: rates, predictors, and relationship to depressive symptomatology. AIDS Behav. 1999;3: 195-204.

18. Perry SW, Card CAL, Moffatt M Jr, Ashman T, Fishman B, Jacobsberg LB. Self-disclosure of HIV infection to sexual partners after repeated counseling. AIDS Educ Prev. 1994;6:403-411.

19. Comer LK, Henker B, Kemeny M, Wyatt G. Illness disclosure and mental health among women with HIV/AIDS. J Commun Appl Soc Psychol. 2000;10:449-464.

20. Derlega VJ, Winstead BA, Greene K, Serovich J, Elwood WN. Perceived HIV-related stigma and HIV disclosure to relationship partners after finding out about the seropositive diagnosis. $J$ Health Psychol. 2002;7:415-432.

21. American Psychiatric Association. Diagnostic and statistical manual of mental disorders. 4th ed. International version. Washington, DC: American Psychiatric Association; 1995.

22. Kaharuza FM, Bunnell R, Moss S, et al. Depression and CD4 cell count among persons with HIV infection in Uganda. AIDS Behav. 2006;10:S105-S111.

23. Nakimuli-Mpungu E, Mutamba B, Othengo M, Musisi S. Psychological distress and adherence to highly active anti-retroviral therapy (HAART) in Uganda: a pilot study. Afr Health Sci. 2009;9:S2-S7.

24. Nakasujja N, Skolasky RL, Musisi S, et al. Depression symptoms and cognitive function among individuals with advanced HIV infection initiating HAART in uganda. BMC Psychiatry. 2010;10:44.

25. Hendershot CS, Stoner SA, Pantalone DW, Simoni JM. Alcohol use and antiretroviral adherence: review and meta-analysis. J Acquir Immune Defic Syndr. 2009;52:180-202.
26. Peltzer K, Friend-du Preez N, Ramlagan S, Anderson J. Antiretroviral treatment adherence among HIV patients in KwaZulu-Natal, South Africa. BMC Public Health. 2010;10:111.

27. Olley BO, Seedat S, Stein DJ. Persistence of psychiatric disorders in a cohort of HIV/AIDS patients in South Africa: a 6-month follow-up study. J Psychosom Res. 2006;61:479-484.

28. Zea MC, Reisen CA, Poppen PJ, Echeverry JJ, Bianchi FT. Disclosure of HIV-positive status to Latino gay men's social networks. Am J Community Psychol. 2004;33:107-116.

29. Kalichman SC, DiMarco M, Austin J, Luke W, DiFonzo K. Stress, social support, and HIV-status disclosure to family and friends among HIV-positive men and women. J Behav Med. 2003;26:315-332.

30. Smith R, Rossetto K, Peterson BL. A meta-analysis of disclosure of one's HIV-positive status, stigma and social support. AIDS Care. 2008; 20(10):1266-1275.

31. Serovich JM, Craft SM, Yoon HJ. Women's HIV disclosure to immediate family. Aids Patient Care STDS. 2007;21:970-980.

32. Marks G, Bundek NI, Richardson JL, Ruiz MS. Self-disclosure of HIV infection: preliminary results from a sample of Hispanic men. Health Psychol. 1992;11:300-306.

33. Kalichman SC, Nachimson D. Self-efficacy and disclosure of HIVpositive serostatus to sex partners. Health Psychol. 1999;18:281-287.

34. Stein MD, Freedberg KA, Sullivan LM, et al. Disclosure of HIV-positive status to partners. Arch Int Med. 1998;15:253-257.

35. Siegal K, Lekas H, Schrimshaw EW. Serostatus disclosure to sexual partners by HIV-infected women before and after the advent of HAART. Women Health. 2005;41:63-85.

36. Ingram KM, Jones DA, Fass RJ, Neidig JL, Song YS. Social support and supportive social interactions: their association with depression among people living with HIV/AIDS. AIDS Care. 1999;11:313-329.

37. Schrimshaw EW. Social support, conflict, and integration among women living with HIV/AIDS. J Appl Soc Psychol. 2002;32:2022-2042.

38. Petrak JA, Doyle AM, Smith A, Skinner C, Hedge B. Factors associated with self-disclosure of HIV serostatus to significant others. Br J Health Psychol. 2001;6:69-79. 


\section{Appendix I \\ Criteria for major depressive episode}

A. Five (or more) of the following symptoms have been present during the same 2-week period and represent a change from previous functioning; at least one of the symptoms is either (1) depressed mood or (2) loss of interest or pleasure.

- Markedly diminished interest or pleasure in all, or almost all, activities most of the day, nearly every day (as indicated by either subjective account or observation made by others)

- Significant weight loss when not dieting or weight gain (eg, a change of more than $5 \%$ of body weight in a month), or decrease or increase in appetite nearly every day. Note: In children, consider failure to make expected weight gains.

- Insomnia or hypersomnia nearly every day

- Psychomotor agitation or retardation nearly every day (observable by others, not merely subjective feelings of restlessness or being slowed down)

- Fatigue or loss of energy nearly every day

- Feelings of worthlessness or excessive or inappropriate guilt (which may be delusional) nearly every day (not merely self-reproach or guilt about being sick)

- Diminished ability to think or concentrate, or indecisiveness, nearly every day (either by subjective account or as observed by others)

- Recurrent thoughts of death (not just fear of dying), recurrent suicidal ideation without a specific plan, or a suicide attempt or a specific plan for committing suicide.

B. The symptoms do not meet criteria for a Mixed Episode (see Criteria for Mixed Episode).
C. The symptoms cause clinically significant distress or impairment in social, occupational, or other important areas of functioning.

D. The symptoms are not due to the direct physiological effects of a substance (eg, a drug of abuse, a medication) or a general medical condition (eg, hypothyroidism).

E. The symptoms are not better accounted for by bereavement, ie, after the loss of a loved one; the symptoms persist for longer than 2 months or are characterized by marked functional impairment, morbid preoccupation with worthlessness, suicidal ideation, psychotic symptoms, or psychomotor retardation.

\section{DSM-IV criteria for alcohol abuse}

A maladaptive pattern of alcohol abuse leading to clinically significant impairment or distress, as manifested by one or more of the following, occurring within a 12-month period:

- Recurrent alcohol use resulting in failure to fulfill major role obligations at work, school, or home (eg, repeated absences or poor work performance related to substance use; substance-related absences, suspensions or expulsions from school; or neglect of children or household).

- Recurrent alcohol use in situations in which it is physically hazardous (eg, driving an automobile or operating a machine).

- Recurrent alcohol-related legal problems (eg, arrests for alcohol-related disorderly conduct).

- Continued alcohol use despite persistent or recurrent social or interpersonal problems caused or exacerbated by the effects of the alcohol (eg, arguments with spouse about consequences of intoxication or physical fights).
Neurobehavioral HIV Medicine

\section{Publish your work in this journal}

Neurobehavioral HIV Medicine is an international, peer-reviewed, open access journal focusing on advances in research in HIV/ AIDS, with specific reference to the neurological, psychiatric and behavioral consequences of the disease, concomitant infections and specific antiretroviral therapy. The manuscript

\section{Dovepress}

management system is completely online and includes a very quick and fair peer-review system, which is all easy to use. Visit http://www.dovepress.com/testimonials.php to read real quotes from published authors. 